\title{
Effect of Supply and Exhaust Air Velocity on the Enthalpy and Temperature Exchange Efficiency of a Paper Heat Exchanger
}

\author{
Hong Jian Hua ${ }^{1}$, Abudulkareem Sh. Mahdi Al-Obaidi ${ }^{1, ~ *}$ Chin Wai Meng ${ }^{2}$, and Kenny \\ James Ling Neng Hui ${ }^{2}$ \\ ${ }^{1}$ School of Computer Science and Engineering, Taylor's University Lakeside Campus, 47500 Subang \\ Jaya, Malaysia \\ ${ }^{2}$ Technology Research Department, Daikin Research \& Development Malaysia Sdn. Bhd., 47000 \\ Sungai Buloh, Malaysia
}

\begin{abstract}
Heat Recovery Ventilators (HRV) are gradually becoming more popular in urban cities and buildings as it is able to effectively maintain the indoor air quality while also using minimal amounts of energy. The key component in the HRV is the Paper Heat Exchanger, which allows the heat exchange of indoor and outdoor air through a crossflow, while also filtering out stale air and dust particles. This article investigates the effect of manipulating the supply and exhaust air velocity on the enthalpy and temperature exchange efficiency of a paper heat exchanger. Data is obtained from experimental results, where the experiments are conducted in a test lab using heat recovery ventilators (HRV) installed with paper heat exchangers. Two paper heat exchangers from different suppliers were tested inside a HRV installed in an air conditioned room. The HRV fan speed was varied at a fixed interval of $0.5 \mathrm{~m} / \mathrm{s}$, and the air velocity was measured by using a wind speed meter. At the same time, a USB data logger was used to collect relative humidity and temperature of the air at the supply inlet, indoor air inlet, and return air outlet to determine temperature exchange efficiency and the enthalpy of air. The results of the testing shows that the HRV was able to achieve a temperature exchange efficiency of 47 to $63 \%$ and enthalpy exchange efficiency of 63 to $94 \%$ for PHEX-A, and a temperature exchange efficiency of 28 to $48 \%$ and enthalpy exchange efficiency of 57 to $85 \%$ for PHEX-B. The data shows that PHEX-A has higher efficiency than PHEX-B.
\end{abstract}

\section{Introduction}

Heat Exchangers are commonly used in many kinds of industries, and a few examples include the heating, ventilation, and air-conditioning (HVAC) industry, automotive industry, and power plants [1-4]. There are many different types of heat exchangers, but for this research paper, emphasis will be put on paper heat exchangers. This research is mainly

\footnotetext{
* Corresponding author: abdulkareem.mahdi@taylors.edu.my
} 
collecting data for the effect of supply and exhaust air velocity on the enthalpy and thermal exchange efficiency of a paper heat exchanger. Data was collected by conducting experiments in collaboration with Daikin R\&D Malaysia (DRDM), as well as by CFD simulations. Focus was put into a specific type of heat exchanger, which is the paper heat exchanger, that is mostly used in Heat Recovery Ventilators (HRV) or Energy Recovery Ventilators (ERV).

The term Paper Heat Exchanger (PHEX) refers to a thin plate-like material that allows fluids to pass through, and these commonly exist in HRVs and act as filters, while allowing heat transfer between outdoor and indoor air. HRVs are commonly installed in buildings where air-conditioning is used, and HRVs are known to be able to reduce load and save energy costs $[2,5]$. HRVs are able to extract waste heat energy from building exhaust air, while providing fresh ventilation and saves energy on heating and cooling load costs [3]. In the modern era, enclosed or 'air-tight' offices are rather common and many people that are working in enclosed offices have high chances of being diagnosed with "tight-building syndrome" due to the poor Indoor Air Quality [4]. Hence, Indoor Air Quality plays an important role which would tremendously affect human's health [5]. Ventilators are important in large buildings, and the implementation of HRVs helps with driving out stale air from a building and replacing it with fresh and cool air from the outdoors without any heating or cooling element $[5,6]$.

Ventilation is a very important aspect in air conditioning, especially during this time of a Covid-19 pandemic [6]. Figure 1 shows how HRV works, and the paper heat exchanger is a part of the HRV painted in red and blue. HRVs function by allowing the stale and warm air in a room to crossflow cool and fresh air from the outdoors, effectively allowing heat exchange while also filtering out fine particles in the air. This heat exchange is a natural process and does not require work done. However, a method to pump air into the ventilator is still required such as with a motorized fan, using minimal energy. HRV requires 3 elements, an accessible source of waste heat, a heat recovery system, and a use for the waste heat that will be recovered. ERVs also use paper heat exchangers, and work in a similar way to the HRVs, with the main difference being that ERVs transfer heat and moisture while HRV only transfers heat [5].

Air-conditioned room

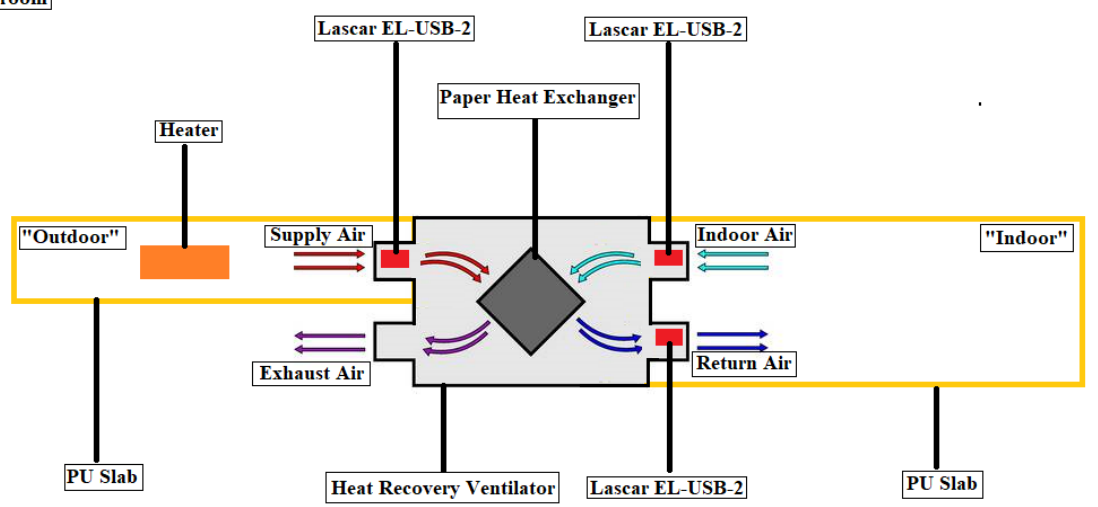

Fig 1. Experimental setup for the research.

\section{Methodology}

This research involves using an HRV unit provided by Daikin, and the testing is done in an enclosed and insulated room. Two PHEX units from different suppliers were used as a 
means to validate the data obtained, and as a repeat of the experiment to check for consistency. The HRV will be placed in a test lab with temperature control features, but the details of the experimental setup and the sources of the PHEX-A and PHEX-B are not disclosed due to confidentiality. There are several testing scenarios, and all the testing conditions are set to be constant, with the return air (RA) condition at $27^{\circ} \mathrm{C}$ and outdoor air (OA) condition at $35^{\circ} \mathrm{C}$. Figure 1 shows the experimental design of the HRV unit with the PHEX installed.

\subsection{Key experimental elements}

Experiments are the method of data collection in this research, and it was carried out in a test laboratory at Daikin R\&D Sdn. Bhd. at Sungai Buloh. The test lab is equipped to control temperature and humidity as to create specific temperature and humidity conditions to collect data. The aim of the experiment is to understand the effect of supply and exhaust air velocity on the enthalpy and temperature exchange efficiency of two paper heat exchangers (PHEX) from different manufacturers. The two PHEX from different manufacturers are used to validate the experimental results and both PHEX were made from similar materials. Hence the performance of both PHEXs will be similar regardless of the Temperature Exchange Efficiency and Enthalpy Exchange Efficiency.

\section{$\underline{\text { Key parameters }}$}

- Relative humidity of the indoor and outdoor air (\%)

- Temperature of the indoor and outdoor air $\left({ }^{\circ} \mathrm{C}\right)$

- The wind velocity of the exhaust fans $(\mathrm{m} / \mathrm{s})$

There are several scenarios to be tested for collection of data, with all of the return air conditions set at $27^{\circ} \mathrm{C}$ and outdoor air conditions at $35^{\circ} \mathrm{C}$. The air velocity will be varied at a fixed interval of $0.5 \mathrm{~m} / \mathrm{s}$, while the difference between each scenario is that the exhaust air velocity is lowered by $15 \%$ each time.

\subsection{Scenario 1}

The HRV unit was first installed with PHEX-A. Return air condition is then set at $27^{\circ} \mathrm{C}$ and outdoor air condition at $35^{\circ} \mathrm{C}$. The supply and exhaust air velocity was varied accordingly at fixed intervals of $0.5 \mathrm{~m} / \mathrm{s}$ and 5 sets of values were taken. The temperature and relative humidity of each air inlet or outlet was measured and recorded for calculations.

\subsection{Scenario 2}

The testing conditions remained unchanged, with the return air condition at $27^{\circ} \mathrm{C}$ and outdoor air condition at $35^{\circ} \mathrm{C}$. The supply and exhaust air velocity was also varied at fixed $0.5 \mathrm{~m} / \mathrm{s}$ intervals, but this time the exhaust air velocity was set at $85 \%$ of supply air velocity. The temperature and relative humidity of all air inlets and outlets were measured and tabulated.

\subsection{Scenario 3}

Similarly, the testing conditions remained unchanged, with the return air condition at $27^{\circ} \mathrm{C}$ and outdoor air condition at $35^{\circ} \mathrm{C}$. The supply and exhaust air velocity was also varied at fixed $0.5 \mathrm{~m} / \mathrm{s}$ intervals, but this time the exhaust air velocity was set at $70 \%$ of supply air 
velocity. The temperature and relative humidity of all air inlets and outlets were measured and tabulated.

\subsection{Repeat of scenario 1, 2 and 3 with PHEX-B}

The PHEX-B was installed into the HRV unit and a repeat of procedures for scenario 1, 2, and 3 was done. All relevant data was recorded and tabulated for calculations.

\subsection{Analysis for temperature exchange efficiency}

By using the temperature values of OA, SA and RA obtained from the experiment, the temperature exchange efficiency can be calculated.

Equation (1) is the formula of temperature exchange efficiency:

$$
\eta_{T}=\frac{T_{\text {Return Air }}-T_{\text {Supply Air }}}{T_{\text {Indoor Air }}-T_{\text {Supply Air }}} \times 100 \%
$$

Equation (1) is the formula of temperature exchange efficiency: where,

$$
\begin{aligned}
& \eta_{T}=\text { Temperature Exchange Efficiency }(\%) \\
& T_{\text {Supply Air }} \quad=\text { Temperature of Outdoor Air }\left({ }^{\circ} \mathrm{C}\right) \\
& T_{\text {Return Air }} \quad=\text { Temperature of Air after Heat Exchanger from Outdoor }\left({ }^{\circ} \mathrm{C}\right) \\
& T_{\text {Indoor Air }} \quad=\text { Temperature of Indoor Air }\left({ }^{\circ} \mathrm{C}\right)
\end{aligned}
$$

\subsection{Analysis for enthalpy exchange efficiency}

For the calculation of enthalpy, a program provided by Daikin was used to quickly calculate the enthalpy values of the air through a digital psychrometric chart. The enthalpy values will be displayed after inputting the values of temperature and relative humidity. The enthalpy values are then tabulated and used to calculate the enthalpy exchange efficiency using the formula.

Equation (2) is the formula of enthalpy exchange efficiency:

Where,

$$
\eta_{h}=\frac{h_{\text {Return Air }}-h_{\text {Supply Air }}}{h_{\text {Indoor Air }}-h_{\text {Supply Air }}} \times 100 \%
$$

$$
\begin{aligned}
& \eta_{h} \quad=\text { Enthalpy Exchange Efficiency }(\%) \\
& h_{\text {Supply Air }}=\text { Enthalpy of Outdoor Air }(\mathrm{kJ} / \mathrm{kg}) \\
& h_{\text {Return Air }}=\text { Enthalpy of Air after Heat Exchanger from Outdoor }(\mathrm{kJ} / \mathrm{kg}) \\
& h_{\text {Indoor Air }}=\text { Enthalpy of Indoor Air }(\mathrm{kJ} / \mathrm{kg})
\end{aligned}
$$

\section{Results and Discussion}

\subsection{Sample data}

The sample data provided in Tables 1 to 3 are from the first experiment scenario, and not all the data collected are included in this conference paper as there are too many tables. The full data will be shown in the thesis paper. 
Table 1. Raw temperature and humidity data of the test lab.

\begin{tabular}{|c|c|c|c|c|c|c|c|c|}
\hline \multirow{2}{*}{$\begin{array}{c}\text { SA \& EA } \\
\text { Velocity }(\mathbf{m} / \mathbf{s})\end{array}$} & \multicolumn{6}{|c|}{ Temperature $\left({ }^{\circ} \mathbf{C}\right)$} & \multicolumn{5}{|c|}{ Relative Humidity $(\%)$} \\
\cline { 2 - 9 } & RA & SA & OA & EA & RA & SA & OA & EA \\
\hline 6.1 & 27.1 & 30.9 & 34.3 & 34.1 & 63.4 & 48.3 & 41.7 & 40.9 \\
\hline 5.6 & 27.0 & 30.4 & 34.3 & 34.2 & 63.6 & 49.2 & 41.0 & 40.5 \\
\hline 5.1 & 27.2 & 30.1 & 34.6 & 34.2 & 61.3 & 48.3 & 42.3 & 40.2 \\
\hline 4.6 & 27.0 & 30.5 & 34.7 & 34.4 & 64.7 & 50.3 & 45.0 & 41.9 \\
\hline 4.1 & 27.0 & 30.7 & 34.9 & 34.5 & 65.0 & 50.5 & 41.9 & 41.2 \\
\hline
\end{tabular}

Table 2. Enthalpy data obtained using psychrometric charts.

\begin{tabular}{|c|c|c|c|}
\hline $\begin{array}{c}\text { SA \& EA } \\
\text { Velocity (m/s) }\end{array}$ & $\begin{array}{c}\text { RA, Enthalpy } \\
(\mathbf{k J} / \mathbf{k g})\end{array}$ & $\begin{array}{c}\text { SA, Enthalpy } \\
(\mathbf{k J} / \mathbf{k g})\end{array}$ & $\begin{array}{c}\text { OA, Enthalpy } \\
(\mathbf{k J} / \mathbf{k g})\end{array}$ \\
\hline 6.1 & 63.7 & 65.7 & 69.9 \\
\hline 5.6 & 63.8 & 64.8 & 69.3 \\
\hline 5.1 & 62.8 & 63.3 & 71.1 \\
\hline 4.6 & 64.1 & 65.9 & 73.4 \\
\hline 4.1 & 64.3 & 66.7 & 72.9 \\
\hline
\end{tabular}

Table 3. Calculated temperature and enthalpy exchange efficiency data.

\begin{tabular}{|c|c|c|}
\hline $\begin{array}{c}\text { SA \& EA } \\
\text { Velocity (m/s) }\end{array}$ & $\begin{array}{c}\text { Temperature } \\
\text { Exchange } \\
\text { Efficiency (\%) }\end{array}$ & $\begin{array}{c}\text { Enthalpy Exchange } \\
\text { Efficiency (\%) }\end{array}$ \\
\hline 6.1 & 47.2 & 67.7 \\
\hline 5.6 & 53.4 & 81.8 \\
\hline 5.1 & 60.8 & 94.0 \\
\hline 4.6 & 54.5 & 80.6 \\
\hline 4.1 & 53.2 & 72.1 \\
\hline
\end{tabular}

RA: Return air, SA: Supply air, OA: Outdoor air, EA: Exhaust air, PHEX: Paper Heat Exchanger

From the sample data, it can be seen that there were fluctuations on all the data obtained, and no reasonable trend for the temperature and relative humidity can be found when the air velocity was varied at a fixed interval. However, after calculations, the temperature and enthalpy exchange efficiency shows an increasing trend as the air velocity was decreased.

\subsection{Results}

Figures 2 to 6 show the graphs of temperature exchange efficiency and enthalpy exchange efficiency for all the scenarios of the experiments conducted using the PHEX-A and PHEXB. A line of best fit was plotted to show the trend of the data.

From the data obtained, it can be seen that there are several trends from the data and graphs. From Figures 2 to 6 , it can be seen that all data shows a trend where as the velocity of air increases, the temperature exchange efficiency and the enthalpy exchange efficiency drops. This data was also supported by similar research done in Universiti Sains Malaysia (USM). The effects of air flow rate on energy recovery shows that the heat recovery efficiency decreases with increasing air velocity [7-10]. This can be explained as when the 
air velocity is slower, the air remains in the same region for a longer period of time, thus absorbing or transferring more heat from the same region [1, 7-8]. Another journal also by Al-Waked et al. also supported the data that the effectiveness of the heat exchanger decreased as the air velocity increased. There were several journals and research papers that were related to the efficiency of a HRV, however due to a lack of a full scale experiment which involves a full building, there is still a gap in the understanding in this field. Further works should be established on a larger scale to fully understand how the thermal exchange efficiency and enthalpy exchange efficiency can affect the performance of a HRV and the ventilation of an entire building [11, 12].

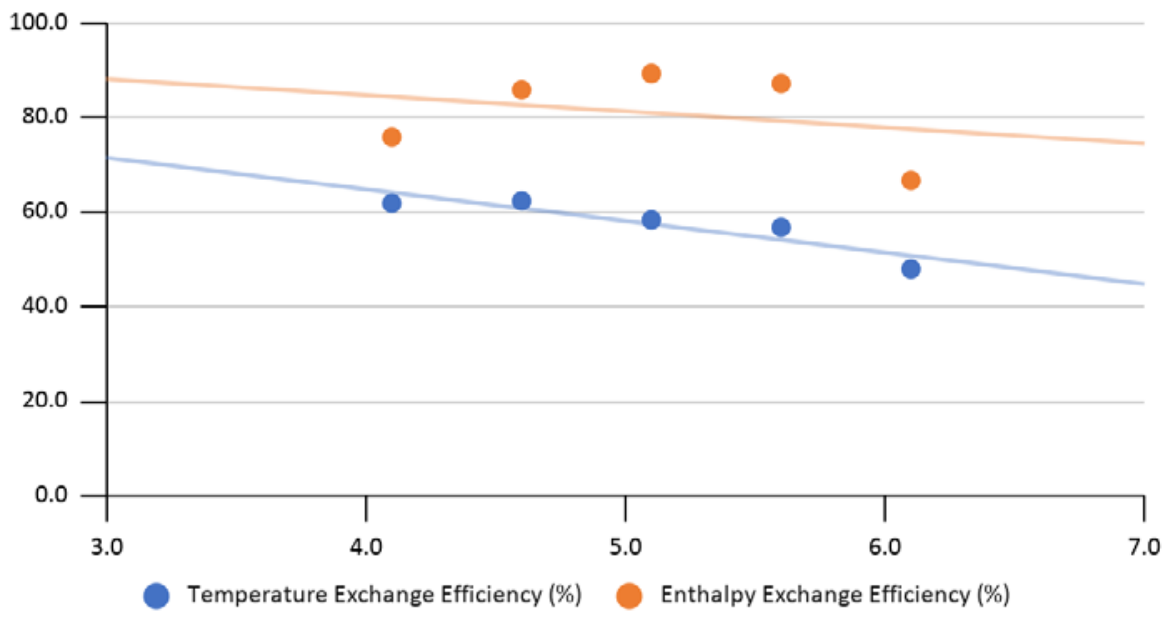

Fig 2. Temperature exchange efficiency and Enthalpy Exchange efficiency against SA and EA Velocity for PHEX-A Scenario 2.

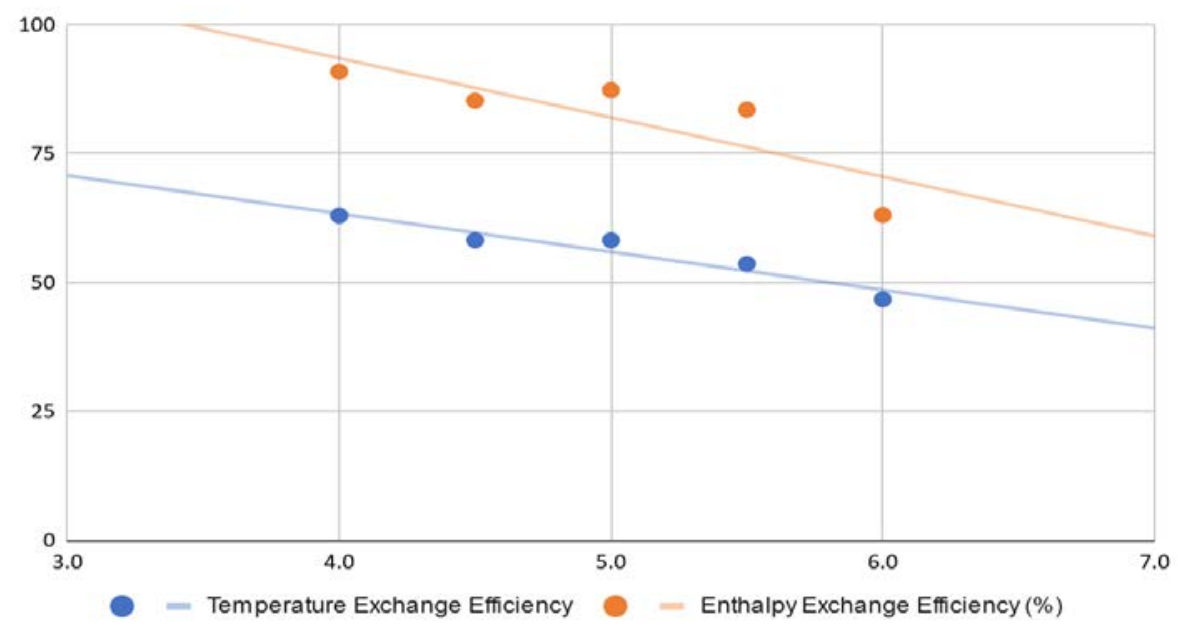

Fig 3. Temperature exchange efficiency and Enthalpy Exchange efficiency against SA and EA Velocity for PHEX-A Scenario 3. 


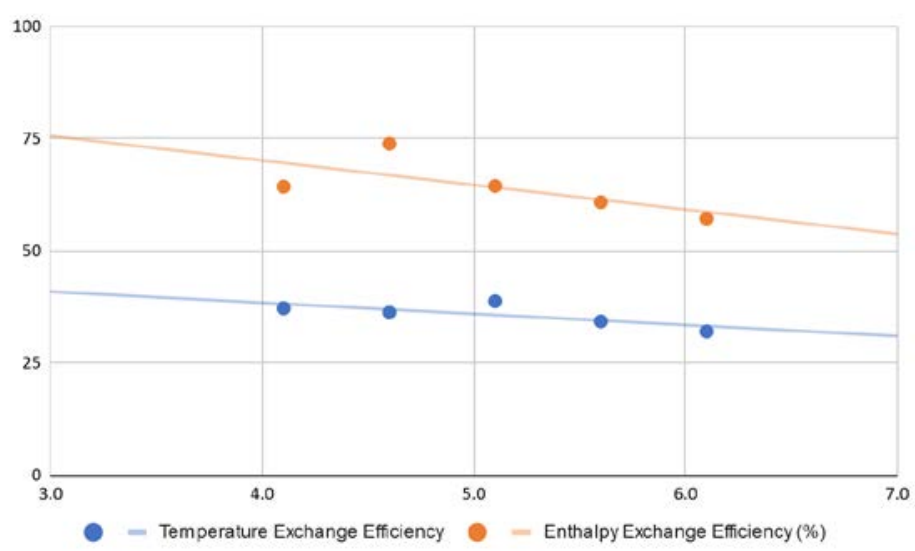

Fig 4. Temperature exchange efficiency and Enthalpy Exchange efficiency against SA and EA Velocity for PHEX-B Scenario 1.

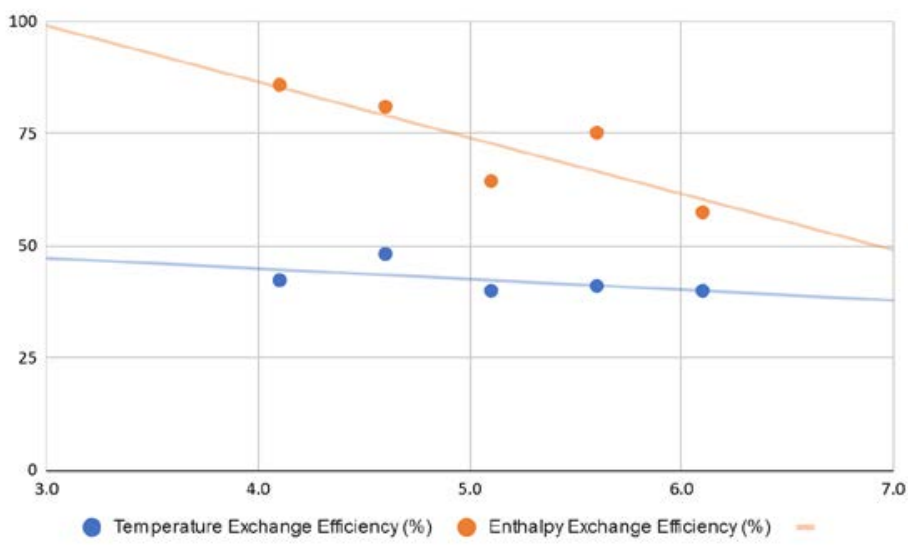

Fig 5. Temperature exchange efficiency and Enthalpy Exchange efficiency against SA and EA Velocity PHEX-B Scenario 2.

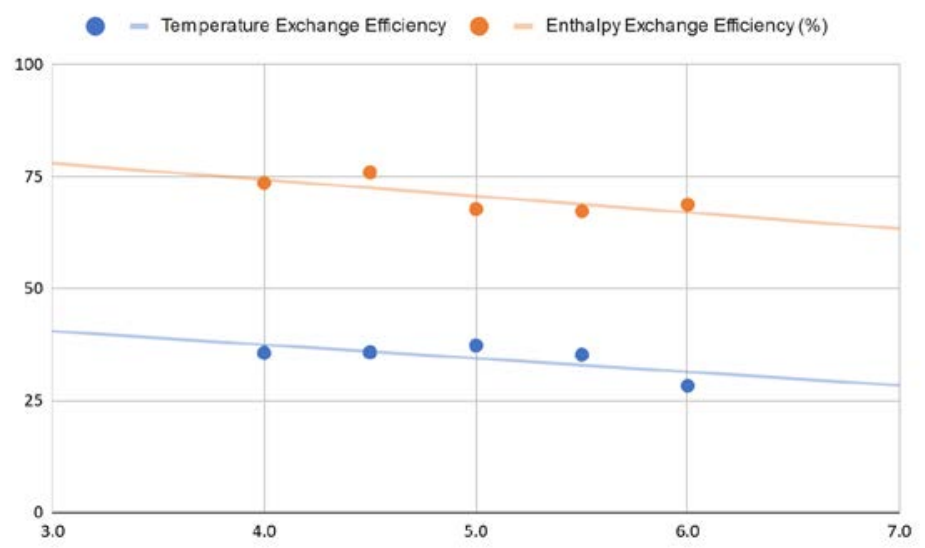

Fig 6. Temperature exchange efficiency and Enthalpy Exchange efficiency against SA and EA Velocity PHEX-B Scenario 3. 
From Figures 2 to 6 , it was also observed that there were large fluctuations in the data collected. Even though an inversely proportional relationship can be seen from the trend lines, there were large amounts of errors present. The errors that were present may have been due to a lack of insulation on the HRV unit, a disturbance in humidity levels during the experiments, and an inconsistent fan motor in the HRV unit. The first possible error was due to a lack of insulation on the HRV unit, as the HRV unit's casing was made using cut metal parts, heat was able to freely exchange through the metal casing. This may have resulted in a temperature change and heat loss. The second possible error was a disturbance in humidity levels due to rain on one of the experiments. As the test room was located on the rooftop, raining would have increased the relative humidity levels of the surrounding areas of the test room. Opening of the door of the test room for data collection during that time may have caused an increase in humidity levels which contributed to errors. The third possible error was having an inconsistent fan motor. During measurement of wind speed, it was found that the motor did not run at a constant speed, and an average air velocity reading had to be taken for the data. The fluctuation in air velocity may also have contributed to the large amount of fluctuations that were seen in the data.

\section{Conclusion}

In this research, adequate amounts of data was collected to analyse the effect of supply and exhaust air velocities on the performance of a paper heat exchanger. The key variables in this experiment were the supply and exhaust air velocity, enthalpy of air, and temperature exchange efficiency. In conclusion, the data obtained and analysed did not support the hypotheses, and the outcome of the experiment found that as the supply and exhaust air velocity increased, the temperature and enthalpy exchange efficiencies decreased. This can be explained as when the air velocity is slower, the air remains in the same region for a longer period of time, thus absorbing or transferring more heat from the same region. The research data collected can serve to improve future paper heat exchanger and HRV designs, and improve quality of life in common office buildings and high-rise apartments. To provide a definitive conclusion, more data will have to be collected in the future, and a repeat of the experiment should be made to validate the results obtained.

This research was supported by Daikin Research and Development Malaysia Sdn. Bhd. and we thank our colleagues from Daikin who have provided insight and expertise that greatly assisted in the research, although they may not agree with all of the conclusions of this research paper. Daikin Research and Development Malaysia Sdn. Bhd. allowed us to conduct experiments in one of their tightly scheduled test labs and provided us with the setup, equipment, and expertise like no other. It was due to their diligence that allowed this research to go smoothly, and we look forward to being able to work with them on future projects or research.

\section{References}

1. K. Akbari, R. Oman, WSEAS Trans. Environ. Dev., 9, 1, 25-31 (2013)

2. L. C. Ng, W. V. Payne, Appl. Therm. Eng. 96, 151-160 (2016)

3. H. Han, Y.-B. Choo, Y.I. Kwon, Proceedings of CLIMA 2007 WellBeing Indoors, (2007)

4. ASHRAE. Standard 62.2-2013: Ventilation and acceptable indoor air quality in lowrise residential buildings. Atlanta: American Society of Heating, Refrigerating and Air-Conditioning Engineers, Inc (2013) 
5. Y. Al horr, M. Arif, M. Katafygiotou, A. Mazroei, A. Kaushik, E. Elsarrag, Int. J. Sustainable Built Environ. 5, 1, 1-11 (2016)

6. J. Atkinson, Y. Chartier, C. L. Pessoa-Silva, P. Jensen, Y. Li, W.-H. Seto, Natural ventilation for infection control in health-care settings. 1st ed. Geneva: World Health Organization Guidelines (2009)

7. Mardiana, A., Riffat, S.B., Renewable Sustainable Energy Rev. 28, 174-190, 11-17 (2013)

8. R. Al-Waked, M. S. Nasif, G. Morrison, M. Behnia, Appl. Therm. Eng., 84, 85-100 (2015)

9. Y. Choi, D. Song, D. Seo, J. Kim, Energy Build., 172, 152-158 (2018)

10. B. Cremers, The Effect of Enthalpy Recovery Ventilation on the Residential Indoor Climate" Zehnder Group Nederland, Lingenstraat 2, 8028 PM Zwolle, The Netherlands, 3-5. (2018)

11. D. M. Ben Guida, Int. J. Innovative Technol. and Explor. Eng., 9, 1, 3713-3715 (2019)

12. S. Huang, W. Li, J. Lu, Y. Li, Procedia Eng., 205, 4105-4110 (2017) 